\title{
Tissue microarray and immunohistochemistry as tools for evaluation of antibodies against Chlamydia-like bacteria
}

\begin{abstract}
Correspondence
Gilbert Greub

gilbert.greub@chuv.ch
\end{abstract}

Received 8 January 2009

Accepted 6 March 2009

\author{
Nicole Borel, ${ }^{1}$ Nicola Casson, ${ }^{2}$ José M. Entenza, ${ }^{3}$ Carmen Kaiser, ${ }^{1}$ \\ Andreas Pospischil ${ }^{1}$ and Gilbert Greub ${ }^{2}$ \\ ${ }^{1}$ Institute of Veterinary Pathology, Vetsuisse Faculty, University of Zurich, Zurich, Switzerland \\ ${ }^{2}$ Center for Research on Intracellular Bacteria, Institute of Microbiology, University of Lausanne, \\ Lausanne, Switzerland \\ ${ }^{3}$ Department of Fundamental Microbiology, University of Lausanne, Lausanne, Switzerland
}

Tissue microarray technology was used to establish immunohistochemistry protocols and to determine the specificity of new antisera against various Chlamydia-like bacteria for future use on formalin-fixed and paraffin-embedded tissues. The antisera exhibited strong reactivity against autologous antigen and closely related heterologous antigen, but no cross-reactivity with distantly related species.

\section{INTRODUCTION}

Several Chlamydia-like bacteria have recently been identified as potential emerging public health threats or pathogenic agents in animals. Parachlamydia acanthamoebae, 'Protochlamydia naegleriophila' and Simkania negevensis have been reported as possible aetiological agents of pneumonia in humans (Casson et al., 2008a; Corsaro \& Greub, 2006; Friedman et al., 2006; Greub et al., 2003). Parachlamydia and related Chlamydia-like organisms have recently been reported in bovine abortion (Borel et al., 2007). Waddlia chondrophila has also been implicated as an abortigenic agent in bovines (Henning et al., 2002; Rurangirwa et al., 1999), and a zoonotic potential for $W$. chondrophila was suggested by an association of antiWaddlia antibodies in women and sustained contact with animals (Baud et al., 2007). Infection may also occur following exposure to water colonized with infected freeliving amoebae. Thus Parachlamydia acanthamoebae strain BN9 has been identified as a symbiont in free-living amoebae (Amann et al., 1997), whereas Parachlamydia acanthamoebae strain Hall's coccus was identified within an amoeba isolated from a humidifier during investigation of an outbreak. 'Candidatus Protochlamydia amoebophila' UWE25 was originally found in an Acanthamoeba isolate from a soil sample (Collingro et al., 2005). 'Criblamydia sequanensis' was isolated from Seine river water using amoebal co-culture (Thomas et al., 2006) and Neochlamydia hartmannellae was detected in Hartmannella vermiformis isolated from the water conduit system of a dental care unit (Horn et al., 2000).

Abbreviations: $\mathrm{HC}$, immunohistochemistry; TMA, tissue microarray.
To define further the possible pathogenic potential of these Chlamydia-like bacteria, new diagnostic tools are needed to demonstrate the agent within tissue lesions. Here, tissue microarray (TMA) technology associated with immunohistochemistry (IHC) was used to determine the specificity of new antisera against various Chlamydia-like bacteria and to investigate the level of cross-reactivity between different Chlamydiales species in formalin-fixed and paraffinembedded pellets.

\section{METHODS}

Acanthamoeba castellanii (ATCC 30010) cultures were infected with Parachlamydia acanthamoebae strain Hall's coccus or strain BN9 (ATCC VR-1476), 'Candidatus Protochlamydia amoebophila' strain UWE25 (ATCC PRA-7), 'Protochlamydia naegleriophila' strain Knic, 'Criblamydia sequanensis' strain CRIB-18, S. negevensis (ATCC VR1471) and $W$. chondrophila (ATCC VR-1470). H. vermiformis strain BL was infected with $N$. hartmannellae (ATCC 50802). Uninfected A. castellanii and $H$. vermiformis cultures were prepared as negative controls.

Vero 76 (ATCC CRL-1587), Caco-2 (ATCC HTB-37) and HEp-2 (ATCC CCL-23) cells were infected with different human and animal chlamydial strains: Chlamydophila pneumoniae strain Kajaaini 6, Chlamydophila abortus strain S26/3 (sheep abortion), Chlamydophila psittaci strain T49/90 (psittacosis agent), Chlamydophila pecorum strain 1710 S (swine origin), Chlamydia trachomatis strain LGV 434 and Chlamydia suis strain S45/6 (swine isolate). Uninfected cell cultures of each cell line served as negative controls. Amoebal and cell pellets were fixed in formalin and embedded in paraffin as described elsewhere (Borel et al., 2006).

A cell culture array block including two equally prepared sets of cell and amoebal pellets was created with the TMA Builder (Histopathology; http://www.histopat.hu) according to the manufacturer's instructions. Briefly, the recipient paraffin block with 24 holes 
of $2 \mathrm{~mm}$ diameter each arranged in four columns and six rows was built using the TMA Builder. The whole cell pellets from the donor blocks were punched out with a Paraffin-Punch-Extractor and arrayed in a preformed recipient paraffin block according to the protocol. Four-micrometre sections were cut using a standard microtome.

For IHC, two commercially available chlamydial antibodies were used: a Chlamydiaceae family-specific mouse monoclonal antibody $(\mathrm{mAb})$ directed against the chlamydial LPS (mLPS; clone ACI-P; Progen) and a Chlamydia-specific mouse mAb (IgG1) directed against recombinant Chlamydia trachomatis Hsp60 (clone A57-B9; Milan Analytica).

Polyclonal mouse antisera for the detection of various Chlamydia-like bacteria were produced previously and characterized by immunofluorescence and Western blotting (Casson et al., 2007). Optimization experiments for antigen retrieval and appropriate dilution of antisera for IHC were performed using infected amoebal and cell pellets. Primary antisera were then applied to the TMA as follows: (i) mLPS at a dilution of $1: 50$, (ii) anti-Hsp60 at a dilution of $1: 1200$, (iii) antiserum against Parachlamydia acanthamoebae strain Hall's coccus at a dilution of 1:6000, (iv) antiserum against 'Protochlamydia naegleriophila' strain Knic at a dilution of 1:20000 and (v) antisera against Parachlamydia acanthamoebae strain BN9, 'Criblamydia sequanensis' and W. chondrophila at dilutions of $1: 40000$.

Detection was performed with a detection kit (ChemMate; Dako) according to the manufacturer's instructions. Briefly, paraffin sections were deparaffinized in xylene and rehydrated through graded ethanol to water. Antigen retrieval was performed by 5 min enzyme digestion (Pronase; Dako) for the mLPS antibody, and repeated microwave heating $(750 \mathrm{~W}$ for $10 \mathrm{~min})$ in citrate buffer, $\mathrm{pH} 6.0$ (Target Retrieval

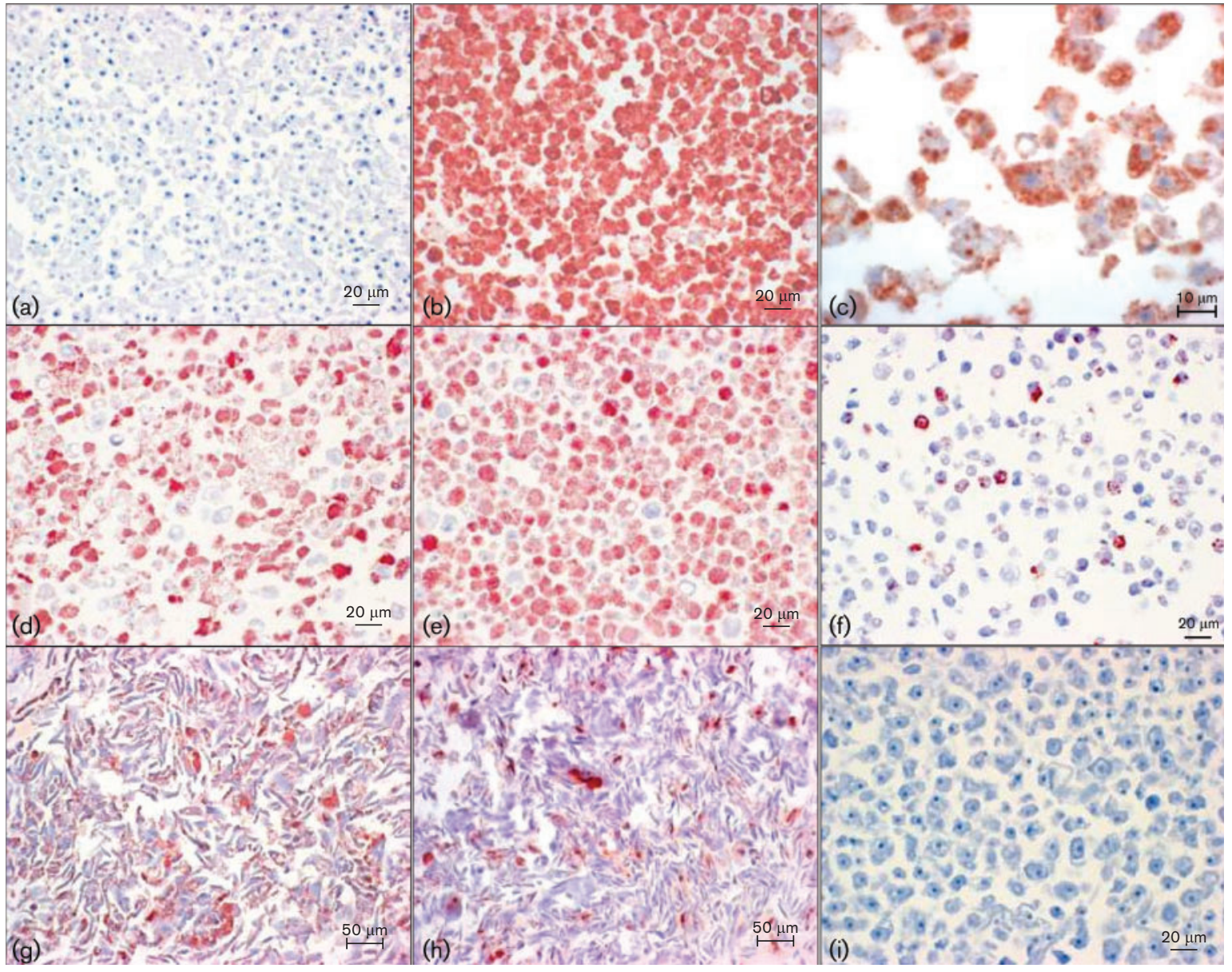

Fig. 1. (a) Uninfected $A$. castellanii. IHC with mouse antiserum against Parachlamydia acanthamoebae strain Hall's coccus $(1: 6000)$. (b, c) A. castellanii infected with Parachlamydia acanthamoebae strain Hall's coccus. IHC with mouse antiserum against Parachlamydia acanthamoebae strain Hall's coccus (1:6000). (d) A. castellanii infected with 'Criblamydia sequanensis'. IHC with mouse antiserum against 'Criblamydia sequanensis' (1:40000). (e) A. castellanii infected with 'Protochlamydia naegleriophila' strain Knic. IHC with mouse antiserum against 'Protochlamydia naegleriophila' strain Knic $(1: 20000)$. (f) A. castellanii infected with 'Criblamydia sequanensis'. IHC with mouse antiserum against W. chondrophila (1:40 000). (g) HEp-2 cells infected with Chlamydophila pneumoniae. IHC with the chlamydial mLPS (1:50). (h) HEp-2 cells infected with Chlamydophila pneumoniae. IHC with a chlamydial anti-Hsp60 antibody (1:1200). (i) Uninfected A. castellanii. IHC with a chlamydial anti-Hsp60 antibody $(1: 1200)$. In all sections, the secondary antibody was detected using 3-amino-9ethylcarbazole/peroxidase and counterstained with haematoxylin. Magnifications: $\times 400$ (a, b, d-f ); $\times 1000$ (c); $\times 200$ (g-i). 
Solution, ChemMate; Dako), for the antisera against Chlamydia-like bacteria. Primary antibodies were incubated for $1 \mathrm{~h}$. For inhibition of endogenous peroxidase activity, the slides were immersed in peroxidase-blocking solution (Dako) for $5 \mathrm{~min}$ at room temperature. Negative and positive controls for each section were included as described elsewhere (Borel et al., 2006).

\section{RESULTS AND DISCUSSION}

The mLPS and anti-Hsp60 antibodies, as well as the antisera against the different Chlamydia-like bacteria, did not exhibit cross-reactivity against uninfected cell or amoebal pellets (Fig. 1a, i). Table 1 shows the antibody titres and cross-reactivities of the different chlamydial antibodies with Chlamydiaceae and Chlamydia-like bacteria, as determined by IHC on the TMA. In general, the antisera exhibited strong reactivity to autologous antigens in amoebal pellets by IHC (Fig. 1b-e). Significant crossreactivity was observed between closely related species, for instance between Parachlamydia and 'Protochlamydia' strains. In contrast, no or little cross-reactivity was detected between distantly related Chlamydia-like bacteria. Surprisingly, the anti-Waddlia antibody cross-reacted with the 'Criblamydia sequanensis'-infected amoebal pellet (Fig. 1f) but not vice versa. Cross-reactivity of the antiserum against Parachlamydia acanthamoebae strain Hall's coccus with 'Protochlamydia naegleriophila' and $N$. hartmannellae was observed once, but could not be confirmed in another experiment and was therefore interpreted as questionable. Vero 76, Caco-2 and HEp-2 cells infected with Chlamydiaceae strains remained negative when tested with all polyclonal mouse antisera, indicating no cross-reactivity between any Chlamydiaceae species and the Chlamydia-like bacteria investigated here. The mLPS antibody reacted with the Chlamydiaceae strains as expected (Fig. 1g), but not with Chlamydia-like bacteria. The same was observed for the anti-Hsp60 antibody (Fig. 1h), except for some cross-reactivity to the pellet infected with $N$. hartmannellae.

Antisera against Parachlamydia acanthamoebae strain Hall's coccus and $W$. chondrophila have already been applied successfully to formalin-fixed and paraffin-embedded bovine placenta specimens and resulted in the first report of Parachlamydia in bovine abortion (Borel et al., 2007). The antibody against Parachlamydia acanthamoebae strain Hall's coccus has also been successfully applied to lung samples from mice experimentally infected with Parachlamydia acanthamoebae: IHC results of lungs correlated well with histopathological lesions and real-time PCR (Casson et al., 2008b).

Reactivity to LPS was not observed in any Chlamydia-like bacteria tested. This suggests that these species do not have a LPS or possess a truncated LPS, as shown for 'Candidatus Protochlamydia amoebophila' UWE25 (Horn et al., 2004). Thus these new agents will not be detected by routine diagnostics when using an antibody directed against chlamydial LPS. Knowledge of the presence of heat-shock proteins in Chlamydia-like bacteria is scarce. Nevertheless, some cross-reactivity of the anti-Hsp60 antibody could be observed in the $N$. hartmannellae-infected amoebal pellet, but not in $H$. vermiformis pellets, suggesting the presence of a heat-shock protein-like structure in this species.

In conclusion, TMA technology in combination with IHC is a useful tool for testing the specificity of antibodies for their future use on formalin-fixed and paraffin-embedded tissues. Possible cross-reactivity of antibodies in closely

Table 1. Dilutions and cross-reactivities of different antibodies with Chlamydiaceae and Chlamydia-like bacteria, as determined by IHC on TMA

\begin{tabular}{|c|c|c|c|c|c|c|c|}
\hline Species studied & $\begin{array}{l}\text { Parachlamydia } \\
\text { acanthamoebae } \\
\text { strain Hall's } \\
\text { coccus }\end{array}$ & $\begin{array}{c}\text { Parachlamydia } \\
\text { acanthamoebae } \\
\text { strain BN9 }\end{array}$ & $\begin{array}{c}\text { 'Protochlamydia } \\
\text { naegleriophila' } \\
\text { strain Knic }\end{array}$ & $\begin{array}{l}\text { 'Criblamydia } \\
\text { sequanensis' }\end{array}$ & $\begin{array}{c}\text { Waddlia } \\
\text { chondrophila }\end{array}$ & LPS & Hsp60 \\
\hline $\begin{array}{l}\text { Parachlamydia acanthamoebae } \\
\text { strain Hall's coccus }\end{array}$ & $1: 6000$ & $1: 40000$ & 0 & 0 & 0 & 0 & 0 \\
\hline $\begin{array}{l}\text { 'Protochlamydia naegleriophila' } \\
\text { strain Knic }\end{array}$ & 0 & 0 & $1: 20000$ & 0 & 0 & 0 & 0 \\
\hline $\begin{array}{l}\text { 'Candidatus Protochlamydia } \\
\text { amoebophila' strain UWE25 }\end{array}$ & $1: 6000^{*}$ & 0 & $1: 20000$ & 0 & 0 & 0 & 0 \\
\hline 'Criblamydia sequanensis' & 0 & 0 & 0 & $1: 40000$ & $1: 40000$ & 0 & 0 \\
\hline Simkania negevensis & 0 & 0 & 0 & 0 & 0 & 0 & 0 \\
\hline
\end{tabular}

${ }^{\star}$ These results were interpreted as questionable, as they were not confirmed in another experiment. 
related species should be considered when investigating human or animal tissues with these antisera by IHC.

\section{ACKNOWLEDGEMENTS}

We would like to thank Dr Urs Ziegler and Dr Claudia Dumrese from the Institute of Anatomy, University of Zurich, Switzerland, for providing Chlamydophila pneumoniae-infected and Chlamydia trachomatis-infected HEp-2 cells. We are grateful to the laboratory staff of the Institute of Veterinary Pathology, University of Zurich. We also thank Sebastien Aeby from the Microbiology Institute of the University of Lausanne for technical help. This research was supported by COST Action 855, Animal Chlamydiosis and Zoonotic Implications, Switzerland (SBF no. C05.0141) and by the Swiss National Science Foundation (grant no. 32003B-116445). G. G. is supported by the Leenards Foundation through a career award entitled 'Bourse Leenards pour la relève académique en médecine clinique à Lausanne’.

\section{REFERENCES}

Amann, R., Springer, N., Schonhuber, E., Ludwig, W., Schmid, E. N., Müller, K. D. \& Michel, R. (1997). Obligate intracellular bacterial parasites of acanthamoebae related to Chlamydia spp. Appl Environ Microbiol 63, 115-121.

Baud, D., Thomas, V., Arafa, A., Regan, I. \& Greub, G. (2007). Waddlia chondrophila, a potential agent of human fetal death. Emerg Infect Dis 13, 1239-1243.

Borel, N., Mukhopadhyay, S., Kaiser, C., Sullivan, E. D., Miller, R. D., Timms, P., Summersgill, J. T., Ramirez, J. A. \& Pospischil, A. (2006). Tissue MicroArray (TMA) analysis of normal and persistent Chlamydophila pneumoniae infection. BMC Infect Dis 6, 152.

Borel, N., Ruhl, S., Casson, N., Kaiser, C., Pospischil, A. \& Greub, G. (2007). Parachlamydia spp. and related Chlamydia-like organisms and bovine abortion. Emerg Infect Dis 13, 1904-1907.

Casson, N., Entenza, J. M. \& Greub, G. (2007). Serological crossreactivity between different Chlamydia-like organisms. J Clin Microbiol 45, 234-236.
Casson, N., Michel, R., Müller, K. D., Aubert, J. D. \& Greub, G. (2008a). Protochlamydia naegleriophila as etiologic agent of pneumonia. Emerg Infect Dis 14, 168-172.

Casson, N., Entenza, J. M., Borel, N., Pospischil, A. \& Greub, G. (2008b). Murine model of pneumonia caused by Parachlamydia acanthamoebae. Microb Pathog 45, 92-97.

Collingro, A., Toenshoff, E. R., Taylor, M. W., Fritsche, T. R., Wagner, M. \& Horn, M. (2005). 'Candidatus Protochlamydia amoebophila', an endosymbiont of Acanthamoeba spp. Int J Syst Evol Microbiol 55, 1863-1866.

Corsaro, D. \& Greub, G. (2006). Pathogenic potential of novel Chlamydiae and diagnostic approaches due to these obligate intracellular bacteria. Clin Microbiol Rev 19, 283-297.

Friedman, M. G., Kahane, S., Dvoskin, B. \& Hartley, J. W. (2006). Detection of Simkania negevensis by culture, PCR, and serology in respiratory tract infection in Cornwall, UK. J Clin Pathol 59, 331-333.

Greub, G., Berger, P., Papazian, L. \& Raoult, D. (2003). Parachlamydiaceae as rare agents of pneumonia. Emerg Infect Dis 9, 755-756.

Henning, K., Schares, G., Granzow, H., Polster, U., Hartmann, M. \& Hotzel, H. (2002). Neospora caninum and Waddlia chondrophila strain 2032/99 in a septic stillborn calf. Vet Microbiol 85, 285-292.

Horn, M., Wagner, M., Muller, K. D., Schmid, E. N., Fritsche, T. R., Schleifer, K. H. \& Michel, R. (2000). Neochlamydia hartmannellae gen. nov., sp. nov. (Parachlamydiaceae), an endoparasite of the amoeba Hartmannella vermiformis. Microbiology 146, 1231-1239.

Horn, M., Collingro, A., Schmitz-Esser, S., Beier, C. L., Purkhold, U., Fartmann, B., Brandt, P., Nyakatura, G. J., Droege, M. \& other authors (2004). Illuminating the evolutionary history of chlamydiae. Science 304, 728-730.

Rurangirwa, F. R., Dilbeck, P. M., Crawford, T. B., McGuire, T. C. \& McElwain, T. F. (1999). Analysis of the $16 \mathrm{~S}$ rRNA gene of microorganism WSU 86-1044 from an aborted bovine fetus reveals that it is a member of the order Chlamydiales: proposal of Waddliaceae fam. nov., Waddlia chondrophila gen. nov., sp. nov. Int J Syst Bacteriol 49, 577-581.

Thomas, V., Casson, N. \& Greub, G. (2006). Criblamydia sequanensis, a new intracellular Chlamydiales isolated from Seine river water using amoebal co-culture. Environ Microbiol 8, 2125-2135. 